\title{
Why should modified Atkins diet be encouraged for treating epilepsy in emerging countries?
}

\author{
Amal Satte ${ }^{2}$, Eric Heath Kossoff ${ }^{1}$, Mohamed Belghiti ${ }^{3}$, Abderrahim Zerhouni², \\ Hamid Ouhabi ${ }^{2}$, Hassania Guerinech ${ }^{3}$, Jamal Mounach ${ }^{2}$
}

1. Department of Neurology and Pediatrics, The Johns Hopkins University, USA

2. Neurophysiology Department, Mohammed V Teaching Military Hospital Mohammed V University, Rabat, Morocco

3. Department of Hygiene and Community Medicine, Mohammed V Teaching Military Hospital Rabat, Morocco

\section{DOI: https://dx.doi.org/10.4314/ahs.v17i2.32}

Cite as: Satte A, Kossoff EH, Belghiti M, Zerhouni A, Oubabi H, Guerinech H, Mounach J. Why should modified Atkins diet be encouraged for treating epilepsy in emerging countries? Afri Health Sci. 2017;17(2): 556-558. bttps://dx.doi.org/10.4314/abs. $v 17 i 2.32$

\section{Introduction}

Epilepsy remains a significant problem of public health in emerging countries. At least 50 million people in the world have epilepsy and approximately $85 \%$ of them live in developing countries ${ }^{1,2,3}$. The high incidence of epilepsy in these countries is often due to parasitic and bacterial infections (such as cysticercosis, toxoplasmosis, hydatid cysts, tuberculosis...), perinatal hypoxia due to poor conditions for home births and maternal diseases, head trauma, toxic agents (including alcohol and drugs), and hereditary factors. ${ }^{4,5}$

Besides the high frequency of epilepsy, treatment in emerging countries is also a problem. A large percentage of the population with epilepsy is not properly treated ${ }^{6}$.

Compounding this issue, many anti-convulsant drugs are also not available. Moreover, these drugs are not affordable for many patients as most people in developing countries lack health insurance. Surgery, if indicated, is also usually either not available, not accessible or not

\section{Corresponding author: \\ Amal Satte, \\ Neurophysiology Department \\ Hôpital Militaire d'Instruction \\ Mohammed V Rabat Maroc \\ Tel: +212 664723716 \\ Email: satteamal@gmail.com}

affordable, as it requires important personal expense in addition to the travel and accommodation expenses.

The direct costs of epilepsy are thus important, but indirect costs are also considerable due to loss of opportunities and productivity. Therefore, there is a genuine need for therapies that would be effective, available and affordable for all patients with epilepsy who can't be adequately treated.

The classic ketogenic diet was developed in 1921. It was designed originally to mimic the ketotic effect of fasting, resulting in an anti-epileptic effect, however it likely works through effects on mitochondria. The International League against Epilepsy has recently become very interested in this therapy as it has gained worldwide attention, including in developing countries ${ }^{7}$ (www.ilae. org/Commission/medther/keto-index.cfm). The classic ketogenic diet (KD) has been widely used and its efficacy and safety have been demonstrated ${ }^{7}$. On the other hand, there has been a tendency in developing countries to use traditional therapies such as plants or special diets. There is also a current trend throughout the world of using non-pharmacological therapies ${ }^{8,9}$. Dietary therapies would be easily accepted as a non-pharmacological therapeutic option with a proved effectiveness and tolerability.

However, the diet can be difficult to adhere to as significant amounts of fats with limited proteins, carbohydrates and fluids have to be used. It is not available in many countries as it requires traditionally a 3-4 day hospitaliza- 
tion with specialized neurologist and dietitian consultation. Though the KD is less expensive than many anticonvulsants, the prices of foods used are relatively high, as even in some developed countries occasional financial difficulties with the diet are reported ${ }^{11}$. On the other hand, calculating a 4:1 ratio ketogenic diet is impossible for an illiterate patient or care giver.

Recently, less restrictive diets have been developed. Among these, the Modified Atkins Diet (MAD) has many advantages, primarily that its efficacy appears in studies to date to be very similar to the classical $\mathrm{KD}^{11,12}$. In MAD, approximately $65 \%$ of calories are from fat sources. It is less restrictive, while still requiring decreased intakes of carbohydrates but with no protein, calorie, or fluid restrictions. Another key difference is that the, MAD does not require hospitalization and can be started as an out-patient without fasting. The MAD has also been reported in two studies to be possible to administer via email to patients without even an in-person clinic visit ${ }^{13,14}$. Another point is that the caregiver or the patient in MAD has to calculate only carbohydrates that should be less than 10 grams per day for children and less than 20 grams for adults, while the $\mathrm{KD}$, calculation is difficult as proteins, fats, carbohydrates and even calories should all be taken into account using computer programs. MAD is thus often easier to start and follow, even if the person who has to prepare the meals has a low level of education.

This is probably one of the strongest points of MAD, as the lowest literacy rates are observed in developing countries. $^{15}$

Another advantage of MAD is that it can be easily adapted to local dishes and traditional recipes. A mediteranean diet, especially the Moroccan one for example, uses vegetables, eggs, meat, olive and argan oil. A patient on MAD would be then able to share the family's meals, with slight modifications, by adding more fat and/or decreasing foods that contain carbohydrates. Dietitian plays an important role in adapting the diet to local eating habits and finding substitutes to sweet ingredients. Wheat flour, for example, can be replaced by hemp flour, almonds or sesame in some dishes.

\section{Conclusion and recommendation}

For all these reasons, we think that dietary therapies, especially MAD, should be encouraged as a therapeutic option in developing countries, not only for drug resistant epilepsy, but also potentially as a first line therapy when medical or surgical treatment isn't available or can't be afforded. MAD is probably the most appropriate in this specific context as its efficacy is similar to the ketogenic diet, but with a better tolerability, ease to use, and less costs. Currently, the diet is used worldwide for the treatment of epilepsy though it was challenging to introduce it in some countries, like Asian countries were customary diets contain less fat than western diets ${ }^{16}$. It would be interesting for African practitioners to share their experience of MAD and assess, through studies, the efficacy and applicability of the diet on the continent.

\section{Conflict of interest}

There is no conflict of interest

\section{References}

1. Epilepsy in the WHO Eastern Mediterranean Region: bridging the gap. World Health Organization. Regional Office for the Eastern Mediterranean.

2. Brundtland GH. The WHO view and launch of the second phase of the Global Campaign Against Epilepsy. Epilepsia 2002, 43(Suppl. 6):5-6.

3. Shorvon SD, Farmer PJ. Epilepsy in developing countries: a review of epidemiological, socio-cultural and treatment aspects. Epilepsia 1998, 29:S36-S54.

4. Bergamasco B, Benna P, Ferrero P et al. Perinatal pathology and epilepsy. Progress in clinical and biological research. 1983; 124: 185-198

5. Senanayake N, Roman GC. Epidemiology of epilepsy in developing countries. Bulletin of the World Health Organization 1993; 71 (2): 247-258

6. Reynolds EH. The ILAE/IBE/WHO Global Campaign against Epilepsy: bringing epilepsy "out of the shadows." Epilepsy Behav 2000; 1:S3-8

7. Neal EG, Chaffe H, Schwartz RH, Lawson MS, Edwards N, Fitzsimmons G, Whitney A, Cross JH. The ketogenic diet for the treatment of childhood epilepsy: a randomized controlled trial. Lancet Neurol 2008; 7(6): 5006

8. www.ilae. org/Commission/medther/keto-index.cfm

9. Benzie IFF, Wachtel-Galor A. Herbal Medicine: Biomolecular and clinical aspects. CRC PRESS/Taylor ans Francis. 2011.

10. ArazeemAbdullahi A. Trends and challenges of traditional Medicine in Africa. Afr J ComplementAltern Med. 2011; 8(5Suppl): 115-123. 
11. Kossoff EH, McGrogan R. Worldwide Use of the Ketogenic Diet. Epilepsia 2005; 46 (2):280-289

12. Miranda MJ, Mortensen M, Povlsen JH, Nielsen H, Beniczky S. Danish study of a Modified Atkins diet for medically intractable epilepsy in children: Can we achieve the same results as with the classical ketogenic diet? Seizure 2011; 20(2):151-5. PubMed

13. Auvin S. Should we routinely use modified Atkins diet instead of regular ketogenic diet to treat children with epilepsy? Seizure 2012; 21(4): 237-40. PubMed 13. Kossoff EH, Dorward JL, Molinero MR, Holden KR. The modified Atkins diet: A potential treatment for developing countries. Epilepsia 2008; 49 (9): 1646-1647

14. Cervenka MC, Terao NN, Bosarge JL, Henry BJ, Klees AA, Morrison PF, Kossoff EH. E-mail management of the modified Atkins Diet for adults with epilepsy is feasible and effective. Epilepsia. 2012 Apr;53(4):728-32 15. UNESCO Institute for Statistics, UIS Fact Sheet, September 2013

16. Kang HC, Kim HD. Diet therapy in refractory pediatric epilepsy: increased efficacy and tolerability. EpilepticDisord. 2006; 8 (4): 309-16. 